\title{
Perspectiva del estudiantado universitario de las diversas carreras de la Universidad Nacional acerca de la democracia en la familia, el centro educativo y el país
}

\section{Perspective of University Students from Different Programs at Universidad Nacional (Costa Rica) regarding Democracy in the Family, Educational Institutions, and the Country}

\author{
María Esther Morales-Ramírez ${ }^{1}$ \\ Universidad Nacional \\ Instituto de Estudios Interdisciplinarios de la Niñez y Adolescencia \\ Heredia, Costa Rica \\ maria.morales.ramirez@una.cr \\ Marianella Castro-Pérez² \\ Universidad Nacional \\ Instituto de Estudios Interdisciplinarios de la Niñez y Adolescencia \\ Heredia, Costa Rica \\ marianella.castro.perez@una.cr \\ Marianela Bolaños-Mora ${ }^{3}$ \\ Universidad Nacional \\ Instituto de Estudios Interdisciplinarios de la Niñez y Adolescencia \\ Heredia, Costa Rica \\ nela.bm@hotmail.com
}

Recibido 24 de febrero de 2014 • Corregido 2 de octubre de 2014 • Aceptado 31 de octubre de 2014

${ }^{1}$ Doctora en Educación con Énfasis en Investigación Educativa. Máster en Psicología Industrial y Organizacional. Licenciada en Psicología. Académica en el Instituto de Estudios Interdisciplinarios de la Niñez y Adolescencia (INEINA) del Centro de Investigación y Docencia en Educación de la Universidad Nacional de Costa Rica.

${ }^{2}$ Máster en Administración Educativa. Licenciada en Educación Preescolar. Académica en el Instituto de Estudios Interdisciplinarios de la Niñez y Adolescencia (INEINA) y de la División de Educación Básica del Centro de Investigación y Docencia en Educación de la Universidad Nacional de Costa Rica.

3 Máster en Pedagogía con énfasis en el Desarrollo y la Atención a la Primera Infancia. Bachiller en Educación Preescolar. Académica en el Instituto de Estudios Interdisciplinarios de la Niñez y Adolescencia (INEINA) de la Universidad Nacional de Costa Rica. 
doi: http://dx.doi.org/10.15359/ree.19-1.11

URL: http://www.una.ac.cr/educare

CORREO: educare@una.cr

Resumen. Este artículo se centra en el tema de la democracia. En este sentido se propuso, como objetivo, analizar la perspectiva del estudiantado universitario de las diversas carreras de la UNA acerca de la democracia en la familia, centro educativo y país. Fue llevado a cabo con base en un sondeo realizado con 138 estudiantes de la Universidad Nacional de Costa Rica, de diversas carreras y niveles de grado. La información se recopiló mediante un cuestionario. Esta se constituye en un insumo para que padres, madres, profesores y autoridades de centros educativos reflexionen en torno a si las dinámicas en las que se desenvuelven en sus respectivos contextos propician la introyección y puesta en práctica de los valores democráticos. Como principal conclusión se podría decir que existe una sensación generalizada de disconformidad y frustración en la población, por el modo en que las administraciones han gobernado el país en los últimos años y, por consiguiente, ante el sistema democrático que impera. En contraposición con esto, la población es cada vez más desconfiada y se muestra renuente a ejercer el derecho que tiene a emitir su voto y a participar activamente. Esto lleva a recomendar que para que la sociedad sea verdaderamente democrática, las familias deberán promover una comunicación asertiva, fundamentada en la comprensión, el respeto, la equidad, la libertad, el afecto, la participación, la igualdad y la colaboración; todo lo cual -cabe pensar-aporta hacia una convivencia armoniosa y pacífica; coadyuva a la formación y el fortalecimiento de los valores cívicos y democráticos que conlleven a la existencia de una verdadera participación ciudadana, desde la primera infancia en los centros educativos hasta los niveles superiores.

Palabras claves. Democracia, libertad, derechos humanos, participación social, toma de decisiones, valores, centro educativo, familia y política.

Abstract. This article focuses on democracy and is aimed at analyzing the perspective of university students from Universidad Nacional de Costa Rica (UNA) regarding democracy in the family, educational institutions as well as the country in general. Research was conducted based on a questionnaire administered to 138 students from different programs and levels at Universidad Nacional de Costa Rica. This research constitutes an input for parents, teachers and educational institution authorities to reflect on whether the dynamics in which they operate in their respective contexts foster the introduction and implementation of democratic values. It was generally concluded that there is an overall feeling of dissatisfaction and frustration experienced by the population, due to the way the different administrations have ruled the country in recent years and, consequently, towards the prevailing democratic system. In addition, the population has become more suspicious and reluctant to exercise their right to vote and actively participate in the process. Consequently, for the society to be truly democratic, families should promote assertive communication based on understanding, respect, fairness, freedom, affection, participation, equality and collaboration. It is appealing to think that all of this will contribute to a harmonious and peaceful coexistence and to the formation and strengthening of civic and democratic values that lead to genuine citizen participation, starting from early childhood in schools and moving to higher levels.

Keywords. Democracy, freedom, human rights, social participation, decision-making process, values, educational institution, family and politics. 
El Instituto de Estudios Interdisciplinarios de la Niñez y la Adolescencia (INEINA), adscrito al Centro de Investigación y Docencia en Educación (CIDE) de la Universidad Nacional de Costa Rica, en el marco del Programa Educación de Calidad, desarrolló el presente artículo, con el objetivo de analizar la perspectiva estudiantil universitaria de diversas carreras de la UNA acerca de la democracia en la familia, centro educativo y país.

Los países, durante el período electoral, tienden a presentar un panorama de incertidumbre ante el cambio, dado el surgimiento de nuevas propuestas de partidos políticos y la experiencia construida por los partidos tradicionales en el ámbito nacional. Frente a este escenario, el pueblo tiene la posibilidad de decidir el futuro del país.

Tradicionalmente, Costa Rica ante el mundo ha sido considerada como una democracia ejemplar, en la que se respeta el derecho del pueblo de decidir acerca de temas de trascendencia política, económica y social; no obstante, desde la perspectiva de las autoras, se tiende a pensar que, cada vez más, el pueblo se siente menos partícipe de esta democracia, incluso se podría decir que existe una sensación de disconformidad con la manera en que las personas que gobiernan han llevado el país en las últimas gestiones presidenciales.

En el año 2005, el Instituto de Estudios Interdisciplinarios de la Niñez y la Adolescencia (INEINA) realizó un sondeo con niños y niñas de centros educativos del país, con el propósito de conocer el concepto de democracia incorporado, así como las expectativas que tenía esta población con respecto a la campaña política que se estaba desarrollando con miras a elegir presidente en el año 2006.

Con base en lo anterior, el Programa Educación de Calidad antes mencionado, consideró pertinente llevar a cabo otro sondeo en la misma temática, a la luz de la nueva campaña política del año 2013, pero esta vez con la comunidad estudiantil de la UNA. El propósito era conocer la opinión respecto al tema de la democracia, cuáles podrían ser algunos de los problemas que vislumbran ellos y ellas en el país, cómo podrían superarse o atenderse, y algunas sugerencias generales al futuro presidente. Asimismo, otras respuestas dan cuenta de su visión sobre cómo se vive la democracia en otros ámbitos tales como el institucional, el de aula, el manejo de las decisiones y sus perspectivas de quiénes deberían estar decidiendo o no sobre los diferentes elementos relacionados con esta temática.

Con miras a enriquecer la vivencia de la democracia y con el deseo de fortalecer los valores democráticos costarricenses, el presente artículo refleja los resultados obtenidos de las respuestas de las personas participantes en el sondeo, de las cuales, además, se derivan una serie de conclusiones y sus correspondientes recomendaciones para el abordaje más asertivo del tema.

\section{Concepto de democracia}

El concepto de democracia nació en Atenas; su base la constituyen las reformas de Solón, razón por la que fue a Clístenes a quien se le asignó el nombre de fundador de la Democracia, sin embargo, los griegos no dejaron escritos sobre el tema (Álvarez, 2010). 
doi: http://dx.doi.org/10.15359/ree.19-1.11

URL: http://www.una.ac.cr/educare

CORREO: educare@una.cr

En nuestro país el tema de la democracia ha sido una de las características que lo han hecho sobresalir sobre muchos otros países, a pesar de ser más pequeño en extensión y población. Nuestros antepasados han hecho un gran esfuerzo por mantenerlo de esta manera, ya que la democracia no ha existido siempre como una forma de vida, justamente por este motivo es nuestro deber valorarla, fortalecerla y tratar de que permanezca. Si bien es cierto, en el ámbito internacional y nacional se concibe la existencia de un régimen democrático prevaleciente en el país, la realidad indica cambios sustanciales en las maneras en que se da la participación ciudadana. Al respecto, Muñoz (2013) plantea que Costa Rica se destaca por la democracia y civilidad de sus habitantes, pero a la vez, "es el país con la más baja participación ciudadana de América Latina y el Caribe" (párr. 5); en opinión de Mata (citada por Muñoz, 2013) "es una paradoja. Esta es una democracia delegativa" (La paradoja, párr. 1).

Desde la perspectiva teórica, democracia quiere decir"el poder del pueblo" derivado de las palabras griegas demos (pueblo) y kratos (poder). Esto significa que es el gobierno del pueblo, por el pueblo y para el pueblo. Por ello, es donde toda la ciudadanía tiene el deber y derecho de participar colectiva o individualmente en la elección de los gobernantes (Álvarez, 2010).

La función principal de la democracia es buscar el bienestar de las personas, reducir las diferencias que existen entre ellas y brindarles la oportunidad de ejercer sus derechos (Diego, 2010). Es un sistema de vida y de gobierno que implica varios aspectos, tal como lo expresa Álvarez (2010):

El derecho de todos los ciudadanos a disfrutar un sistema democrático; la soberanía del pueblo; la tolerancia como expresión de respeto hacia las personas que no piensan como nosotros; el pluralismo como el juego de los distintos pensamientos y concepciones de las corrientes políticas participan en una democracia, son expresiones operativas de los valores que nos inspiran. (p. 73)

La palabra democracia es muy mencionada en el ámbito político y, precisamente, comienza en las elecciones de un gobernante para el país. Estas elecciones deben ser siempre libres, justas y transparentes, como resultado de su significado; pero no queda ahí, ya que en opinión de Álvarez (2010) incluye: "el diálogo, el pluralismo, la tolerancia, la reconciliación, la búsqueda del consenso, el respeto de los derechos de las minorías, a la división e independencia de los poderes y la participación de los ciudadanos y ciudadanas" (p. 74).

Esto quiere decir que la democracia, para estar completa, debe abarcar los ámbitos político, económico, social, además del cultural y ser guiada tanto por la concepción del ser humano como de la sociedad (Morales, 2008). Es un sistema de vida que busca la realización de metas individuales y grupales de las personas, familias y sociedad, sin hacer distinción, discriminación ni exclusión de ningún tipo. 
La democracia en sí requiere de varios principios para ser organizada, los cuales son comentados por Rodríguez (2009, p. 8):

- En una democracia, la solución de los problemas, se hace mediante el uso de la razón, conducida por la voluntad de la mayoría. La capacidad racional de los individuos, es la que guía y orienta el comportamiento de los miembros de la sociedad democrática.

- La democracia es un modo de actuar, que tiene ciertas características. Se brinda la posibilidad de realizar acciones personales y sociales. Es decir, hay libertad para pensar y actuar. La libertad es uno de los pilares fundamentales de la democracia.

- Si el modo de actuar pretende lograr metas que interesen a todos y ofrecer la posibilidad de que todos puedan compartir, sin distingos ni discriminaciones, entonces se puede decir que en una democracia, hay participación, dentro de la sociedad civil organizada.

- En la democracia, las personas pueden participar en todos los niveles de decisión que se relacionen con su modo de vida, individual o colectivamente.

- En una democracia, las personas deben participar activamente, en la búsqueda de una sociedad más justa y solidaria.

- En una democracia, se le brinda a las personas, las familias y la comunidad, la posibilidad de lograr metas que interesen a todos y que brinden la oportunidad de que todos puedan compartir, sin distingos ni discriminaciones, o sea, existe la igualdad.

\section{La democracia en la familia}

En el modelo de familia democrática, la autoridad sigue siendo asunto del padre y de la madre, aunque no impuesta ni complaciente, pero sí compartiendo las responsabilidades dependiendo de la edad de cada miembro de la familia y de sus capacidades (Luengo y Moyá, 2008).

Este estilo de familia es el que debe existir en todos los hogares de nuestro país para que así prevalezca la democracia en la sociedad, ya que este modelo es caracterizado por la comunicación constante, la comprensión, igualdad y colaboración de todos sus miembros (Ramírez, 2005).

Para que una familia funcione de manera democrática deben presentar niveles altos en comunicación, afecto, control y exigencias de madurez. En otras palabras, dan afecto, refuerzan el comportamiento, no utilizan el castigo y están atentos a las peticiones de los niños y niñas; dirigiendo y controlando las capacidades; además, dan explicaciones y no ceden ante el capricho, y plantean exigencias e independencia (Ramírez, 2005). Cuando una familia se considera democrática, la opinión de todos y todas es muy importante, el ser escuchados, comprendidos y tomados en cuenta se vuelve una forma de vida, la cual ayuda a que la convivencia en familia sea más placentera, madura y participativa (Ramírez, 2011). 
doi: http://dx.doi.org/10.15359/ree.19-1.11

URL: http://www.una.ac.cr/educare

CORREO: educare@una.cr

Agrega Ramírez (2011) que la decisión de estructurar la familia con base en el diálogo como principio fundamental lleva a que todos y todas sean reconocidos, convirtiendo en un derecho la toma de las decisiones familiares de manera grupal y tomando en cuenta los sentimientos, preocupaciones e intereses de todos sus participantes.

Nuestro país respalda legalmente el derecho que tienen los niños, niñas y adolescentes a expresar su opinión, primeramente, con la Convención sobre los derechos del niño (Fondo Internacional de Emergenia de la Naciones Unidas para la Infancia [UNICEF], 2005, pp. 13-14), la que en el artículo 12 plantea:

1. Los Estados Partes garantizarán al niño que esté en condiciones de formarse un juicio propio el derecho de expresar su opinión libremente en todos los asuntos que afectan al niño, teniéndose debidamente en cuenta las opiniones del niño, en función de la edad y madurez del niño.

2. Con tal fin, se dará en particular al niño oportunidad de ser escuchado, en todo procedimiento judicial o administrativo que afecte al niño, ya sea directamente $o$ por medio de un representante o de un órgano apropiado, en consonancia con las normas del procedimiento de la ley nacional.

Además, acerca del derecho de audiencia, el Código de la Niñez y la Adolescencia. Ley 7739 (1998) menciona, en el artículo 114 inciso f que "en todos los procesos administrativos y judiciales relacionados con los derechos de esa población se escuchará su opinión" (p. 43).

Esto nos lleva a la conclusión de que cada miembro de la familia es importante, por lo tanto, su opinión es valiosa y debe ser tomada en cuenta en el hogar. Aparte de que es un derecho que todos y todas tenemos, hablando de democracia, es la manera más justa de tomar decisiones.

Los niños, niñas y adolescentes son personas en desarrollo y a la vez sujetos de derechos; no obstante, y justamente por lo anterior, su vulnerabilidad es superior a la de las personas adultas, por lo tanto, se considera que requieren mayor protección tal y como lo explica Pellegrini (2009). Al respecto, la misma autora refiere que "la intensidad de dicha protección puede ser tal que obstaculice o directamente anule la posibilidad de asumir paulatinamente el pleno goce y disfrute de los derechos" (p. 2).

Partiendo de lo antes mencionado, se puede decir:

Que el concepto de autonomía progresiva aparece como un parámetro de equilibrio entre el reconocimiento de los niños como protagonistas activos de su propia vida, con la prerrogativa de ser escuchados y respetados y de que se les conceda una autonomía cada vez mayor en el ejercicio de sus derechos, y la necesidad que tienen, al mismo tiempo, 
de recibir protección en función de su relativa inmadurez y menor edad. Este concepto constituye la base de un apropiado respeto de la conducta independiente de los niños, sin exponerlos prematuramente a las plenas responsabilidades normalmente asociadas con la edad adulta. (Lansdown, citado por Pellegrini, 2009, p. 2)

Con la aplicación del concepto de la autonomía progresiva los niños, niñas, adolescentes y jóvenes "adquieren mayores competencias, aumenta [sic] su capacidad de asumir responsabilidades, disminuyendo consecuentemente la necesidad de orientación y dirección de sus padres, contenido y finalidad de la responsabilidad parental" (Pellegrini, 2009, p. 2).

Asimismo, añade que la progresividad en la adquisición de competencias para el ejercicio de los derechos en estas poblaciones se relaciona directamente con la madurez y el desarrollo de sus facultades, así como con la naturaleza del derecho a ejercer, en este caso, el derecho a la participación, decisión y opinión en los diferentes contextos o escenarios en los que se desarrollan estas personas jóvenes.

\section{La democracia en el centro educativo}

En opinión de Cepeda (2011-2012), "son precisamente los espacios educativos, aquellos que se presentan como los escenarios óptimos para la formación de auténticos ciudadanos que hagan uso pleno de sus derechos consagrados en la Constitución" (p. 52), así como el de contribuir a que se dé una verdadera ciudadanía participativa, "que haga uso del derecho a la información y se fortalezca, finalmente, nuestra democracia" (p. 52).

Por lo anterior, el rol de la población docente debería ser facilitar y apoyar la labor y el liderazgo del estudiantado, en donde todos y todas deben tratarse por igual con el objetivo del pleno desarrollo del aprendizaje y las habilidades personales. El aula es un lugar público en donde se puede hablar, compartir y expresar nuestros sentimientos y experiencias que generan una ciudadanía activa (Luengo y Moyá, 2008). Por eso, en la clase debe haber siempre una interacción de pensamientos, en donde haya libertad, tolerancia y respeto mutuo, y donde todos y todas actúen pensando en el valor de la democracia que se aprende o no, en el centro educativo (Arias, 2010).

Al respecto, Villegas (1996, citando a Rauner) se refiere a la discusión en torno a la estrecha relación que existe entre la democracia y la educación, y si es viable la existencia de la democracia en ausencia de la educación. Rifkin (citado por Villegas, 1996), apoya el planteamiento precitado, al apuntar que no existen países democráticos cuya población no esté educada. Acerca de este mismo punto, Villegas (1996) señala que "la educación es una condición necesaria, pero no suficiente, para la existencia de una democracia; y ... que no todo tipo de educación garantiza democracia" (p. 266), por lo que sugiere que es imperativa la educación en valores en los centros educativos. El objetivo de esta debe ser formar a las generaciones más jóvenes como una ciudadanía democrática, capaz de hacer frente a los retos que demanda el mantener regímenes democráticos efectivos, caracterizados 
doi: http://dx.doi.org/10.15359/ree.19-1.11

URL: http://www.una.ac.cr/educare

CORREO: educare@una.cr

por una asertiva educación moral y por la convivencia pacífica. En esta formación, no cabe duda del papel preponderante de los diferentes actores que conforman la comunidad educativa, mediante la dinámica personal y la interacción con sus semejantes. Específicamente a lo interno del salón de clases, se considera relevante que las estrategias pedagógicas que se pongan en práctica para la formación de personas democráticas sean consecuentes.

La toma de decisiones es un proceso en el cual se definen los problemas, en donde hay una recopilación de datos, se crean alternativas y se selecciona la acción. En el salón de clase las decisiones se toman en grupo, ya que se convive grupalmente (Malave, 2012). Las condiciones en que se deben tomar estas decisiones se clasifican en reglas e inciertos. La primera, se refiere a los reglamentos generales que deben existir para que prevalezca el respeto y el orden; la segunda se refiere a la definición de problemas e identificación de posibles soluciones y consecuencias (Malave, 2012).

Para que las decisiones en una institución educativa sean democráticas, se debe tener claro el camino a seguir y para lograr esto se deben evaluar las acciones de cada participante de la clase, incluido el personal docente facilitador.

Según Mucherino (citado por Malave, 2012, Condiciones en las que se toman las decisiones, párr. 10) existen cinco tipos de decisiones dentro del aula:

- Diagnóstico: La información básica concierne al conocimiento existente, habilidades, actitudes, intereses, etc. del alumno, en particular relacionados con los objetivos...

- Selección: a) el resultado del diagnóstico, b) la preferencia del alumno, c) el conocimiento de los profesores acerca de los recursos existentes y de la disponibilidad de los materiales en la clase, en el momento específico de la decisión.

- Participación. Esta es la velocidad con que el alumno responda en una unidad o, si la actividad es en grupo, el horario existente. Lo importante es saber en qué momento el alumno considera que conoce a fondo los objetivos de la unidad.

- Evaluación. La información básica es la actuación del alumno en función de los objetivos para la unidad.

- Motivación. La información básica es el éxito del alumno en función de una actividad preestablecida (como una unidad), de las preferencias del alumno, la disponibilidad y el tiempo determinado para la actividad".

En opinión de Mucherino (citado por Malave, 2012), queda claro que en las decisiones del aula intervienen la persona docente con una participación diaria y activa, además de los alumnos y alumnas. 
Cabe resaltar la imperante necesidad de que la formación en valores cívicos y democráticos que promuevan una verdadera participación ciudadana, se inicie desde niveles tempranos en los centros educativos y no que se visualice como una función exclusiva de las universidades, lo cual es coherente con lo estipulado en los fines de la Ley Fundamental de Educación (Asamblea Legislativa de la República de Costa Rica, 1957), en el artículo 2, inciso a. y b. a saber: "La formación de ciudadanos amantes de su Patria, conscientes de sus deberes, de sus derechos y de sus libertades fundamentales, con profundo sentido de responsabilidad y de respeto a la dignidad humana; c) Formar ciudadanos para una democracia en que se concilien los intereses del individuo con los de la comunidad" (p. 1).

En esta misma línea, es trascendental el rol que también deben cumplir los centros de educación superior, en el "fortalecimiento de ciudadanía participativa cívica y civilizada dentro del marco de la cultura de la legalidad; lo que no sólo impactará positivamente en el uso del derecho de acceso a la información, sino también en otras áreas como las leyes de participación ciudadana en las entidades federativas, y que la sociedad pueda ser protagonista activa de la construcción de la agenda nacional y del diseño, implementación y evaluación de las políticas públicas en su conjunto" Cepeda, 2011 - 2012, p. 59).

\section{Democracia en el país}

Rodríguez (2009) hace referencia a que un país es democrático cuando se pone en "ejercicio de la participación, en la sociedad, sin distingos de ninguna clase y ejerciendo plenamente la libertad y la igualdad" (p. 9). En otras palabras, se toma en cuenta la opinión de cada miembro de la sociedad, sin distingo de género, edad, nivel económico ni social.

Además, el secreto de una sociedad democrática es formar un equilibrio en la distribución de poder de tal manera que evite el dominio de personas o grupos sobre otros (Luengo y Moyá, 2008). Para que esto se logre, se debe tomar en cuenta que la democracia tiene varios procesos; uno de ellas es elegir a un gobernante; otro, la forma de gobierno; y otro, el ejercicio de los principios de libertad, igualdad, racionalidad, moralidad y participación popular (Rodríguez, 2009).

El régimen democrático es regido por cuatro valores fundamentales: la igualdad, libertad de opinión, participación abierta para todos y todas, y la fraternidad entre los ciudadanos (Luengo y Moyá, 2008), en donde la forma de organización del gobierno se convierte en una convivencia social en la cual las decisiones son colectivas, justas: es aquí donde se hace valer la democracia.

Existen muchos aspectos relacionados con las características de los países democráticos. Dahl (citado por Furlong, 2008) señala que un requisito indispensable es tener "elecciones libres, abiertas y competitivas" (p. 7). Agrega, demás, que la poliarquía (o democracia) es un orden político que se caracteriza por la presencia de cinco características: 
doi: http://dx.doi.org/10.15359/ree.19-1.11

URL: http://www.una.ac.cr/educare

CORREO: educare@una.cr

- Los candidatos elegidos: El control sobre las decisiones gubernamentales en política se otorga a funcionarios elegidos constitucionalmente.

- Las elecciones libres y justas: Los candidatos elegidos se escogen en elecciones frecuentes y justas, don de la coerción es relativamente rara.

- El sufragio universal: Prácticamente todos los adultos tienen el derecho a votar en el proceso electoral.

- El derecho a postularse como candidato: Prácticamente todos los adultos tienen derecho a ser elegidos como gobernantes, aunque los límites de edad pueden ser mayores para ser elegibles que para ejercer el sufragio.

- Información alternativa: Los ciudadanos tienen derecho a buscar otras fuentes alternas de información. Es más, esas fuentes deben existir y estar protegidas por la ley. (p. 7)

Furlong (2008) plantea que un país democrático se fundamenta en diferentes valores que son interdependientes $y$, al mismo tiempo, complementarios. Promueven la dignidad, el desarrollo y el bienestar humano, sin hacer exclusión de personas ni de los valores entre sí. Los principales valores que menciona son la libertad, la igualdad, la justicia y la solidaridad.

No obstante, con respecto a lo anterior, Álvarez (2010) opina que otro valor importante que debemos tomar en cuenta es la paz, entendida no solamente como ausencia de guerra, sino más bien de tolerancia, no-violencia y reconciliación. Para él, la democracia no se considera sostenible si no existen los valores de la paz ni la cultura cívica.

Villegas (1996) da cuenta del poco conocimiento que posee la población latinoamericana acerca de las implicaciones que conlleva la convivencia cotidiana democrática y de la verdadera puesta en práctica de valores cívicos democráticos en sus creencias y conducta diaria.

Acerca de este punto, Muñoz (2013), con base en el Informe Nacional sobre Desarrollo Humano del 2013, señala que Costa Rica se destaca por la democracia y civilidad de sus habitantes; empero, se coloca como el país con la más baja participación ciudadana de América Latina y el Caribe.

Aunado a lo anterior, Furlong (2008) reitera el bajo lugar en la escala democrática en que se ubica Costa Rica, "debido al alto nivel de corrupción política percibida en su sistema"(p.5). Además, enfrenta diversos desafíos como problemas sociales y económicos que necesitan solución y el autor antes mencionado reafirma su posición en el hecho de que en Costa Rica "hay problemas estructurales en el sistema... la burocracia es ineficaz y lenta, la corrupción y los partidos políticos ... están perdiendo apoyo popular" (p. 181). Además "el abstencionismo, se ha convertido en uno de los desafíos fundamentales para la democracia costarricense y el sistema político" (p. 254). 
Otro de los principales problemas de Costa Rica es el interés por ver solamente los aspectos negativos o desfavorables de la sociedad. Las personas con el transcurso del tiempo han ido decepcionándose de la democracia por causa del trabajo ineficaz de los políticos, que no cumplen ni satisfacen los que el pueblo necesita (Obregón, 2009).

Adicionado a lo anterior, Muñoz (2013), califica la democracia costarricense como "una democracia delegativa" (p. 2), ya que la población indica estar altamente satisfecha con su vida, Este sentimiento se refleja a través del "pura vida" como forma "des-complicada" que le permite evadir compromisos duraderos y trascendentales para sí mismos y el país. Añade que los "habitantes de este país suelen delegar la responsabilidad de lo colectivo al Estado" (p. 3). Imperando un invididualismo muy antiguo (Ramírez, citado por Muñoz, 2013).

En opinión de Cepeda (2011-2012), lo anterior "trae como resultado una sociedad pasiva, en espera de los incentivos económicos y sociales para paliar su situación social, acostumbrada a recibir y a padecer aletargada, en espera de soluciones institucionales" (p. 49).

Ante estas problemáticas, según Álvarez (2010), la solución que necesita el país es "avanzar hacia nuevos niveles de desarrollo humano con optimismo, esperanza, liderazgo y metas claras" (p. 236). Además recalca que "es tiempo de retomar el espíritu cívico y de cumplir con el deber ciudadano de alimentar con el voto el sistema de la democracia" (p. 236), ya que se ha dejado de lado esta opción como medio de supervivencia de la democracia y, a su vez, se ha olvidado que el voto, aparte de ser un deber, es un privilegio en Costa Rica y que no todos los países lo disfrutan, por lo que lo mejor es hacer uso de él como estrategia para mantener una democracia sostenible.

Asimismo, García (s. f.) plantea que en el sistema político se podrán aplicar dos cualidades, a saber: la inteligencia y la responsabilidad, en las que podría confiarse para que la democracia resista.

En virtud de lo anterior, Álvarez (2010) comenta que la forma de gobierno en todos los pueblos de América debería ser la democracia, por lo que sus gobernantes tienen el deber de promoverla y defenderla, como condición fundamental para promover el desarrollo económico, social y político del país. Al respecto, Furlong (2008) resalta el papel determinante que tiene el gobierno en la reducción de las desigualdades que en los diferentes ámbitos impactan negativamente a la población que vive en Costa Rica.

\section{Marco metodológico}

El presente artículo se realizó utilizando los datos obtenidos en un sondeo. En este sentido, el enfoque del proceso indagativo es mixto, ya que complementa datos cuantitativos con cualitativos. El tipo de estudio es descriptivo, ya que muestra los datos tal cual fueron obtenidos o brindados por las personas consultadas, a fin de señalar conceptos, características, rasgos, propiedades de la democracia en el caso particular. 
doi: http://dx.doi.org/10.15359/ree.19-1.11

URL: http://www.una.ac.cr/educare

CORREO: educare@una.cr

\section{Participantes}

El estudio se realizó en la Universidad Nacional de Costa Rica, Campus Omar Dengo, con una población conformada por 138 estudiantes de diversas carreras y niveles de grado. La selección de participantes se realizó al azar; se tomó en cuenta la disposición del profesorado a facilitar al grupo para completar el instrumento durante su clase y que el grupo de estudiantes estuvieran en disposición de responderlo.

\section{Instrumentos}

El instrumento utilizado para la recopilación de la información fue un cuestionario, dirigido a estudiantes universitarios, de conformidad con lo especificado en el párrafo anterior. Este se estructuró con preguntas tanto abiertas como cerradas para un total de 13. Según su contenido, las preguntas utilizadas son de identificación, profundización en la actitud de la persona, de creencia y de opinión. Las cerradas se formularon con el propósito de caracterizar a la población participante, en tanto que las abiertas permiten tener elementos referidos a la percepción de la puesta en práctica de la democracia en las decisiones familiares, del centro educativo y del país.

\section{Procedimientos}

En primera instancia, para fundamentar teóricamente el tema, se procedió a realizar una búsqueda bibliográfica. Posteriormente, se coordinó con el profesorado de la UNA, acerca de la viabilidad de aplicar, a estudiantes que mostraran disposición a hacerlo, el instrumento diseñado.

Una vez que se contó con los datos, se elaboraron las categorías de análisis y seguidamente las tablas para su descripción y, a partir de ello, se plantearon conclusiones y recomendaciones.

\section{Análisis de datos}

Es importante hacer referencia a que para el análisis de los datos obtenidos mediante el instrumento diseñado para el sondeo, las investigadoras tomaron la decisión, con respecto a la cantidad de personas participantes, de incluir la totalidad de las respuestas brindadas y reflejadas en los totales de cada tabla, debido a dos aspectos: primero, a que la muestra es pequeña; y segundo y de mayor peso, no perder la riqueza de las respuestas de aquellas personas que ampliaron su reflexión e incluso brindaron su criterio con diferentes significados acerca del tema.

Por otra parte, cabe señalar que las tablas que se presentan en este artículo, contienen respuestas agrupadas en categorías emergentes de análisis, estas no reflejan la totalidad de las opiniones textuales, debido a que las tablas quedarían de gran tamaño.

Para iniciar, se presentan los datos que describen o caracterizan a la población participante. 


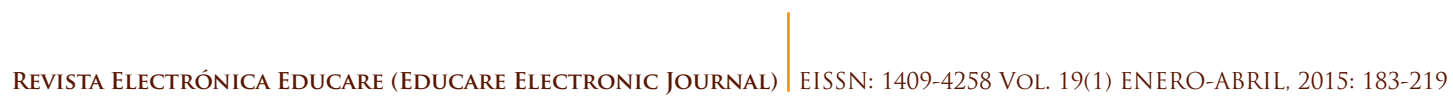

doi: http://dx.doi.org/10.15359/ree.19-1.11

URL: http://www.una.ac.cr/educare

CORREO: educare@una.cr

En este sentido, se puede decir que la mayoría (82.6\%) de los participantes son jóvenes costarricenses entre los 17 a 25 años, estudiantes de la UNA que están iniciando o concluyendo su carrera de grado.

Tabla 1

Carrera que cursan las personas participantes

\begin{tabular}{lcc}
\hline \multicolumn{1}{c}{ Categoría } & Frecuencia & $\%$ \\
\hline Historia & 40 & 28.9 \\
Educación preescolar & 20 & 14.4 \\
Enseñanza del arte y comunicación visual & 19 & 13.7 \\
Educación rural l y ll ciclo & 13 & 9.4 \\
Enseñanza de las ciencias & 7 & 5.1 \\
Enseñanza del inglés & 7 & 5.1 \\
Educación comercial & 5 & 3.6 \\
Educación musical & 4 & 2.9 \\
Informática educativa & 4 & 2.9 \\
Enseñanza del francés & 3 & 2.2 \\
Educación física & 3 & 2.2 \\
Estudios sociales & 3 & 2.2 \\
Psicología & 3 & 2.2 \\
Desarrollo costarricense & 1 & 0.72 \\
Español & 1 & 0.7 \\
Filosofía & 1 & 0.7 \\
Educación especial & 1 & 0.7 \\
Administración de empresas & 1 & 0.7 \\
Topografía & 13 & 0.7 \\
Iy ll ciclo & 100.0 \\
\hline Total & 1 & 0.7 \\
\hline & & \\
\hline
\end{tabular}


doi: http://dx.doi.org/10.15359/ree.19-1.11

URL: http://www.una.ac.cr/educare

CORREO: educare@una.cr

La tabla 1 es explícita en que, mayoritariamente, las personas participantes tienen carreras relacionadas con ciencias de la educación en los diferentes niveles (preescolar hasta secundaria) y énfasis. Otras personas cursan carreras como administración de empresas, topografía, psicología, entre otras.

La población estudiantil colaboradora cursa los niveles desde primero a cuarto en mayor porcentaje, pocas personas se encuentran en quinto nivel o en categoría de egresados y en las carreras que cursan hay una alta prevalencia de mujeres.

En resumen, se puede decir que la población participante se caracteriza por ser jóvenes costarricenses, con mayor representación femenina, y se ubican en diferentes niveles de carreras de grado, principalmente relacionadas con las ciencias de la educación.

Tabla 2

¿Para usted qué significa democracia?

\begin{tabular}{lcc}
\hline Categoría & Frecuencia & $\%$ \\
\hline Derecho a elegir /Toma de decisiones & 55 & 29.1 \\
Libertad de expresión & 36 & 19.1 \\
Poder/Participación del pueblo & 19 & 10.1 \\
Tomar en cuenta la opinión del pueblo & 13 & 6.91 \\
Igualdad /lgualdad de derechos/ Reconocer la diversidad & 21 & 11.16 \\
Aspectos políticos, sociales, económicos, culturales & 8 & 4.25 \\
Libertad & 6 & 3.19 \\
Respeto a los demás/patria & 5 & 2.65 \\
Valores del país & 5 & 2.65 \\
Voz y voto & 4 & 2.12 \\
Poder, tiranía de los gobernantes & 4 & 2.12 \\
Convivir pacíicamente & 3 & 1.59 \\
Derechos y deberes & 2 & 1.06 \\
Otros & 6 & 3.18 \\
No responde & 1 & 0.53 \\
\hline Total & 188 & 100.0 \\
\hline
\end{tabular}


La tabla 2 hace referencia al concepto de democracia. Desde la perspectiva de las personas participantes, este consiste, principalmente, en el derecho del pueblo a elegir y tomar decisiones acerca de los temas de orden social, político, económico y cultural. Asimismo, se menciona que es la libertad de expresión y participación en los diferentes ámbitos que conforman la sociedad, incorporan otros elementos tales como la opinión, la igualdad, la libertad, el respeto, el voto y la voz del pueblo.

En este sentido, la teoría que respalda o sustenta el presente sondeo menciona que la democracia atribuye el poder al conjunto de la sociedad, donde las decisiones demandan la participación del pueblo, visto este como un grupo de iguales con los mismos derechos y deberes. Incluso en la teoría se menciona la posibilidad de que los ciudadanos puedan elegir por medio del voto o sufragio a sus autoridades, en aras de favorecer el consenso, el respeto de los derechos, la independencia y la participación ciudadana. Finalmente, cabe decir que según lo muestran las respuestas y tal como lo afirma Rodríguez, 2009, hay coincidencia al señalar que "la libertad es uno de los pilares fundamentales de la democracia" (p. 8).

Tabla 3

¿Para usted qué es una familia democrática?

\begin{tabular}{lcc}
\hline \multicolumn{1}{c}{ Categoría } & Frecuencia & $\%$ \\
\hline Se decide tomando en cuenta la opinión de todos/ se toman decisiones en conjunto & 49 & 27.2 \\
/Se respeta decisión de la mayoría de los miembros & & \\
Se tiene libertad de expresión & 19 & 10.6 \\
Se respeta & 16 & 8.9 \\
Se le da importancia al aspecto político & 15 & 8.3 \\
Se presenta la igualdad y justicia & 14 & 7.8 \\
Se establece comunicación & 11 & 6.1 \\
Se practiquen los valores & 11 & 6.1 \\
Se muestra participación & 7 & 3.9 \\
Se vive la libertad & 7 & 3.9 \\
Se da el derecho a voz y voto & 6 & 3.3 \\
Se practica el apoyo mutuo & 5 & 2.8 \\
Todos tienen derechos y deberes & 4 & 2.2 \\
Se compartes características & 3 & 1.7 \\
Se busca el bien común & 3 & 1.7 \\
Se observan reglas definidas & 3 \\
Otros & 3 & 1.7 \\
No sabe & 2 & 1.1 \\
\hline Total & 5 & 2.8 \\
\hline
\end{tabular}


doi: http://dx.doi.org/10.15359/ree.19-1.11

URL: http://www.una.ac.cr/educare

CORREO: educare@una.cr

La información de la tabla 3 refleja la gran cantidad de personas que coinciden en que, en una familia democrática, se toman decisiones considerando la opinión de la totalidad de sus integrantes y respetando lo que demanda la mayoría de ellos y ellas. En este sentido, cobra importancia la libertad de expresión y el respeto, entre otros valores como la justicia, igualdad, comunicación, participación.

Los elementos anteriores, determinan la posibilidad de tener voz y voto en todos los aspectos que competen a sus miembros. Este modelo, según se menciona en la teoría, es el más indicado, sano y difícil de implementar, por lo que representa un desafío en el establecimiento de límites y normas, y en el manejo de la autoridad ejercida con respeto, libertad y amor (Rodríguez, 2011).

Tabla 4

¿Qué se requiere para tener una familia democrática?

\begin{tabular}{|c|c|c|}
\hline Categoría & Frecuencia & $\%$ \\
\hline Respeto & 51 & 18.4 \\
\hline Comunicación/Diálogo /Libertad de expresión/ Escucharse & 37 & 13.4 \\
\hline Igualdad/Equidad & 20 & 7.2 \\
\hline Tolerancia & 19 & 6.8 \\
\hline Tener valores/Principios & 17 & 6.1 \\
\hline Una buena unión/Relación familiar & 10 & 3.6 \\
\hline Practicar el patriotismo & 9 & 3.2 \\
\hline Amor & 8 & 2.8 \\
\hline Tomar decisiones en conjunto & 8 & 2.8 \\
\hline Comprensión & 7 & 2.5 \\
\hline Participación/Colaboración & 7 & 2.5 \\
\hline Interés/Compromiso & 5 & 1.8 \\
\hline Educación & 5 & 1.8 \\
\hline Valorar a los miembros de la familia & 4 & 1.4 \\
\hline Tener libertad & 4 & 1.4 \\
\hline Paciencia & 4 & 1.4 \\
\hline Responsabilidad & 4 & 1.4 \\
\hline Personas abiertas de mente & 3 & 1.0 \\
\hline Que haya confianza & 3 & 1.0 \\
\hline Respetar la diversidad & 2 & \\
\hline Otros: Trabajo en equipo, luchar por la familia, ser flexibles, justicia & 24 & 8.6 \\
\hline No responde & 22 & 7.9 \\
\hline No sabe & 3 & 1.0 \\
\hline Total & 276 & 100 \\
\hline
\end{tabular}

Nota: Se toman dos respuestas por persona. 
Los datos en la tabla 4 evidencian que las respuestas dadas por las personas participantes demandan la existencia de una serie de valores positivos como elemento primordial para que la familia sea democrática. En este sentido, los valores que sobresalen son: el respeto con alrededor del 18.4\%, la comunicación, el diálogo, la escucha y la libre expresión con un 13.4\% aproximadamente y la equidad e igualdad con casi un $7.2 \%$. De la misma manera, se enumeran otros valores con frecuencias inferiores, pero que también se consideran importantes para fortalecer la democracia de la familia como son la paciencia, la responsabilidad y la confianza, entre otros, lo cual coincide con las características que, en opinión de Ramírez (2005), debe poseer una familia democrática.

Tabla 5

¿En cuáles decisiones deben participar los hijos e hijas?

\begin{tabular}{lcc}
\hline \multicolumn{1}{c}{ Categoría } & Frecuencia & $\%$ \\
\hline En las que estén involucrados & 44 & 29.7 \\
En todas & 41 & 27.7 \\
En las de la familia & 20 & 13.5 \\
Las acordes con su edad/madurez/ en las que sean capaces & 9 & 6.1 \\
En la mayoría & 6 & 4.1 \\
En asuntos personales & 4 & 2.7 \\
En educación & 4 & 2.7 \\
Las que sean necesarias & 3 & 2.0 \\
Otras & 11 & 7.5 \\
No sabe & 2 & 1.4 \\
No responde & 4 & 2.7 \\
\hline Total & 148 & 100.0 \\
\hline
\end{tabular}

Según se observa, en las respuestas brindadas en la tabla 5, alrededor de un tercio de la población considera que los hijos e hijas deben coadyuvar en la toma de decisiones en las que estén involucrados. Esto hace pensar que están excluidos de algunas de las decisiones que se toman, ya que los adultos deciden en cuáles les concierne o compete. No obstante, una cantidad similar de personas comenta que deben participar en todos los acuerdos familiares.

Un grupo resalta que deben tenerse la oportunidad de decidir de acuerdo con la capacidad, madurez y edad de los hijos e hijas, siendo esto coherente con la autonomía progresiva expresada en el nuevo paradigma de derechos de las personas menores edad. 
Asimismo Luengo y Moyá (2008) subrayan dos aspectos fundamentales: en la familia democrática, la autoridad es y sigue siendo competencia de los padres y madres de familia; no obstante, se comparten responsabilidades y decisiones con los hijos e hijas, dependiendo de la edad y de sus capacidades. Cabe retomar las palabras de Ramírez (2011), quien menciona que en una familia democrática, la opinión de todos y todas es importante, así como la escucha y la comprensión, por ser elementos que se conjugan para una convivencia sana, madura, participativa y placentera.

Tabla 6

¿Considera usted que en la UNA hay democracia?

\begin{tabular}{lcc}
\hline Categoría & Frecuencia & $\%$ \\
\hline Sí & 86 & 62.3 \\
No & 41 & 29.7 \\
Más o menos & 3 & 2.3 \\
No responde & 8 & 5.8 \\
\hline Total & 138 & 100.0 \\
\hline
\end{tabular}

Tal como se observa en la tabla 6 anterior, más del $60 \%$ de las personas que respondieron el cuestionario consideran que en la Universidad Nacional de Costa Rica sí hay democracia. Mientras tanto, alrededor de un $30 \%$ opina lo opuesto, es decir, que no estudian en una universidad democrática. Para ambas respuestas (positiva o negativa) estas personas brindaron las razones que justifican su opinión, las tablas 7 y 8 las muestran.

Tabla 7

¿Por qué sí hay democracia?

\begin{tabular}{lcc}
\hline \multicolumn{1}{c}{ Categoría } & Frecuencia & $\%$ \\
\hline Permiten la participación estudiantil & 14 & 16.3 \\
Se toma en cuenta a los estudiantes & 13 & 15.1 \\
A veces sí, a veces no & 10 & 11.6 \\
Nos podemos expresar & 8 & 9.3 \\
Se respetan los derechos & 7 & 8.1 \\
Existe libertad & 5 & 5.8 \\
Comunican lo que pasa & 1 & 1.2 \\
No responde & 28 & 32.6 \\
\hline Total & 86 & 100.0 \\
\hline
\end{tabular}


Del total de las respuestas afirmativas referidas a que en la UNA hay democracia, se crearon las categorías emergentes que se muestran en la tabla 7, antes presentada. De estas se deduce que los estudiantes consideran que sí hay democracia, debido a que se permite su participación, se les toma en cuenta, se pueden expresar, se respetan sus derechos, sienten libertad y reciben comunicación de lo que sucede en la universidad.

Santos (1995, citado por Prieto, 2003) mencionó que se requiere fomentar la participación a partir del diálogo permanente, el debate abierto y la crítica efectiva para lograr instituciones educativas democráticas, de lo contrario, se impide la generación de procesos de colaboración y reciprocidad.

Tabla 8

¿Por qué no hay democracia?

\begin{tabular}{lcc}
\hline Categoría & Frecuencia & $\%$ \\
\hline No se le pide opinión al estudiantado & 15 & 36.5 \\
No existe autonomía ni libertad, todo es política & 9 & 21.9 \\
Solo las autoridades toman decisiones & 8 & 19.5 \\
No hay comunicación & 4 & 9.7 \\
Otros & 5 & 12.1 \\
\hline Total & 41 & 100.0 \\
\hline
\end{tabular}

En la tabla 8 se evidencia que del total de 41 personas que opinaron que no hay democracia en la UNA, alrededor de un 37\% considera que esto se debe a que no se pide opinión a los estudiantes en los diversos temas y aspectos universitarios; un $22 \%$ menciona la falta de autonomía, libertad y el manejo político que impide el ejercicio democrático; un $19.5 \%$ afirma que las decisiones se toman únicamente con la participación de las autoridades; finalmente, un aproximado al 10\% menciona que los canales de comunicación no se dan en los temas que le competen directamente a la comunidad estudiantil y, por ende, tampoco en otras áreas. 
Revista Electrónica Educare (EdUCARE EleCtronic JOURNAL) EISSN: 1409-4258 VOL. 19(1) ENERO-ABRIL, 2015: 183-219

doi: http://dx.doi.org/10.15359/ree.19-1.11

URL: http://www.una.ac.cr/educare

CORREO: educare@una.cr

Tabla 9

¿Propiamente en el aula, cómo considera usted que se aplica la democracia?

\begin{tabular}{lcc}
\hline \multicolumn{1}{c}{ Categoría } & Frecuencia & $\%$ \\
\hline Respetando la opinión, derechos, intereses & 32 & 20.6 \\
Mediante la discusión del programa del curso & 14 & 9.0 \\
Dando libertad de expresión & 13 & 8.4 \\
Depende del profesor & 11 & 7.1 \\
Tomando decisiones en grupo & 11 & 7.1 \\
Permitiendo la participación & 11 & 7.1 \\
Escuchando la opinión & 10 & 6.5 \\
Casi nunca se da & 6 & 3.9 \\
Mediante la comunicación profesor-estudiante & 5 & 3.2 \\
Solo algunas veces se aplica & 5 & 3.2 \\
En la relación profesor-estudiante & 5 & 3.2 \\
Dando oportunidades a los estudiantes & 3 & 2.0 \\
Los profesores dan el ejemplo & 2 & 1.3 \\
Respeto entre compañeros & 2 & 1.3 \\
Otros & 14 & 9.0 \\
No aplica & 4 & 2.6 \\
No responde & 4 & 2.6 \\
No sabe & 3 & 1.9 \\
\hline Total & 155 & 100.0 \\
\hline
\end{tabular}

Las acciones generadas dentro del aula y consideradas como muestra de la existencia o no de la democracia son variadas, tal y como se observa en la tabla 9. Quienes sí visualizan estos procesos en los ambientes educativos mencionan que son escuchadas y respetadas sus opiniones, derechos e intereses, se discute el programa de curso con ellos y ellas, se da libertad de expresión, se toman decisiones en grupo, se permite la participación del estudiante, se establece comunicación bidireccional entre el profesorado y los educandos, se brindan oportunidades a la población universitaria, los profesores modelan conductas y además existe el respeto entre compañeros y compañeras. 
Al respecto, la bibliografía señala que evidentemente a lo interno de las aulas se requiere de participación, respeto, voz, tolerancia, un manejo respetuoso de la disciplina y las normas, reconocimiento de los estudiantes como sujetos éticos, capaces de aportar a la construcción del bien común (Prieto, 2003). Esta misma autora advierte que el alumnado no puede sentirse parte de lo que hace y tomar conciencia de las responsabilidades que sus decisiones implican, si no vivencia, incluso desde los niveles inferiores de la educación, la democracia en las aulas. Es necesario, señala, que los estudiantes participen y expresen sus voces para el desarrollo de las habilidades analítica y crítica para discernir y escoger, así como para que aprendan a pensar y actuar autónomamente, resolver conflictos, y desarrollar la conciencia social y autoconciencia para ejercer su libertad.

Tabla 10

¿Cuáles decisiones le corresponde tomar al estudiantado?

\begin{tabular}{lcc}
\hline \multicolumn{1}{c}{ Categoría } & Frecuencia & $\%$ \\
\hline Las decisiones que lo involucren & 47 & 32.0 \\
Las relacionadas con el curso & 38 & 25.9 \\
En los relacionados con el programa del curso & 10 & 6.8 \\
En todas debe participar & 9 & 6.1 \\
En los relacionados con el estudio & 8 & 5.4 \\
En las elecciones & 5 & 3.4 \\
En el respeto al profesorado & 4 & 2.7 \\
Depende del profesorado & 2 & 1.4 \\
En la evaluación & 2 & 1.4 \\
Las mismas que al profesorado & 1 & 0.7 \\
Otras & 14 & 9.5 \\
No responde & 7 & 4.8 \\
\hline Total & 147 & 100.0 \\
\hline
\end{tabular}

La tabla 10 muestra que las personas entrevistadas piensan que deben ser partícipes en la toma de decisiones que tienen que ver con cursos que reciben, tales como el diseño del programa y la evaluación, entre otras. Llama la atención que el porcentaje mayoritario señala textualmente que desea participar en las decisiones que los involucre, no especificando a qué se refieren. 
REVISTA EleCtrónica EdUCARE (EDUCARE EleCtronic JOURNAL) EISSN: 1409-4258 VOL. 19(1) ENERO-ABRIL, 2015: 183-219

doi: http://dx.doi.org/10.15359/ree.19-1.11

URL: http://www.una.ac.cr/educare

CORREO: educare@una.cr

Por otra parte, comentan que deberían estar involucrados e involucradas en "todas las decisiones" (6.1\%), en las elecciones (3.4\%), en las relacionadas con el personal docente y con el grado de participación que se les da a la población estudiantil, entre otras.

Tabla 11

¿Cuáles decisiones le corresponde tomar al profesorado?

\begin{tabular}{lcc}
\hline \multicolumn{1}{c}{ Categoría } & Frecuencia & $\%$ \\
\hline & & \\
La organización de la clase/ Diseño de propuestas/ & 49 & 29.2 \\
estrategias/ evaluación/ contenidos & 27 & 16.1 \\
Las académicas /Las que le competen como docente & 14 & 8.3 \\
La mediación con estudiantes & 10 & 6.0 \\
Las que respetan las decisiones de estudiantes & 10 & 6.0 \\
Todas/La mayoría & 6 & 3.6 \\
Los aspectos que se deben mejorar & 6 & 3.6 \\
Las que fortalecen la relación profesorado-estudiante & 5 & 3.0 \\
Las que afecten a docente y estudiantes & 4 & 2.4 \\
Las que se toman con sus estudiantes & 4 & 2.4 \\
Las adecuadas para el estudiantado & 4 & 2.4 \\
Las que crean importantes/ necesarias & 3 & 1.8 \\
El establecimiento de límites, reglas y valores & 2 & 1.2 \\
Depende del profesorado & 168 & 1.2 \\
Las que favorezcan la educación & 2 & 8.3 \\
Otras & 14 & 4.8 \\
No responde / No sabe & 2 & \\
\hline Total & & \\
\hline
\end{tabular}

Desde la perspectiva de los estudiantes y las estudiantes participantes, expuesta en la tabla 11, se tiene que al personal docente le corresponde tomar decisiones relacionadas con la organización de la clase, diseño de contenidos, estrategias y evaluación, las académicas o las de su competencia como docentes, como lo concerniente a la mediación, límites, reglas y valores. 
Esto es consecuente con lo indicado por la población participante al señalar en la tabla 14, que a la mayoría les gustaría tomar parte en las decisiones relacionadas con los aspectos relativos al curso en conjunto con el personal profesional responsable. Solo un $6 \%$ considera que es el profesorado quien debe decidir acerca de la mayoría o todos los componentes del curso. Un grupo (3.6\%) hace la salvedad de que la persona docente debe velar por el fortalecimiento de la relación "docente-estudiante" y para que se respeten las opiniones estudiantiles (6\%).

Tabla 12

¿Cuáles decisiones le corresponde tomar a ambos (docentes y estudiantes)?

\begin{tabular}{lcc}
\hline Categoría & Frecuencia & $\%$ \\
\hline Las relacionadas con el aprendizaje /con la & 55 & 35.2 \\
evaluación/ con la metodología utilizada /La & & \\
construcción de conocimiento & 30 & 19.2 \\
En las que participen ambos & 15 & 9.6 \\
En todas & 10 & 6.4 \\
Las que promueven un buen ambiente & 7 & 4.5 \\
Las que ayuden a mejorar & 3 & 1.9 \\
Las que solucionan problemas & 2 & 1.3 \\
Las que propician el bienestar de la totalidad & 2 & 1.3 \\
Los temas de interés & 14 & 9.0 \\
Otras & 4 & 2.6 \\
No aplica & 14 & 9.0 \\
No responde & 156 & 100.0 \\
\hline Total & & \\
\hline
\end{tabular}

En la tabla 12, se pueden observar que las decisiones atribuidas a ambos grupos de personas (docentes y estudiantes) se relacionan con la labor académica (aprendizaje, evaluación y metodología). Asimismo se mencionan aquellas en las que tengan participación ambos grupos; no obstante, algunos consideran que deben involucrarse en todas las decisiones, como por ejemplo: las que promueven un buen ambiente, las que ayuden a mejorar, las que buscan solución de problemas el bienestar de todos y las que sean de interés para ellos y ellas, siendo esto coincidente con lo planteado por Malave (2012), respecto a los tipos de decisiones que se toman dentro del aula. 
doi: http://dx.doi.org/10.15359/ree.19-1.11

URL: http://www.una.ac.cr/educare

CORREO: educare@una.cr

Tabla 13

¿Cómo describiría un país democrático?

\begin{tabular}{lcc}
\hline \multicolumn{1}{c}{ Categoría } & Frecuencia & $\%$ \\
\hline Donde haya libertad de expresión / Donde hay libertad de elección / Donde hay libertad & 39 & 20.3 \\
Donde haya igualdad & 15 & 16.3 \\
El pueblo es escuchado y cuenta su opinión & 31 & 16.1 \\
El pueblo puede tomar decisiones / Se toman decisiones en conjunto /El pueblo & 23 & 12 \\
participa en las decisiones & & \\
Busca el bienestar del pueblo/ El que vela por los intereses del pueblo & 17 & 8.9 \\
No existe la democracia & 9 & 4.7 \\
Es el que respeta al pueblo & 8 & 4.2 \\
Donde hay paz & 6 & 3.1 \\
Donde se respetan los derechos & 5 & 2.6 \\
Aquel donde no existe corrupción & 5 & 2.6 \\
Promueve la buena comunicación/información & 4 & 2.1 \\
El que no tiene ejército & 4 & 2.1 \\
Un pueblo que no se deje llevar & 3 & 1.6 \\
Se promueven los valores & 3 & 1.6 \\
Donde existen leyes y se respetan & 3 & 1.6 \\
El que sabe lo que hace & 3.2 \\
Donde el pueblo es el gobernante & 100.0 \\
Otros & 3 & 2 \\
No responde & 2 & 1.0 \\
\hline Total & 2 & 4.1 \\
\hline & 2 & 2 \\
\hline
\end{tabular}

Alrededor de un $20 \%$ de las personas participantes coinciden en señalar que la democracia se evidencia en un país cuando este tiene libertad tanto para expresarse como para elegir a sus gobernantes y para vivir en general. Otros valores importantes que se apuntan tienen que ver con la igualdad, la paz y el respeto; fundamentales todos en un sistema democrático, según la opinión estudiantil. 


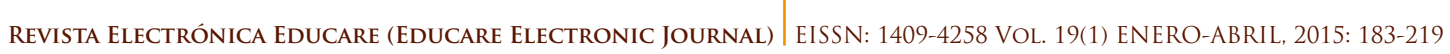

doi: http://dx.doi.org/10.15359/ree.19-1.11

URL: http://www.una.ac.cr/educare

CORREO: educare@una.cr

En porcentaje similar,(16.1\%) ellos y ellas comenta que una característica de un país democrático es que los ciudadanos son escuchados y sus opiniones son tomadas en cuenta. De igual manera, tal y como se refleja en la tabla 13, otras respuestas dan cuenta de un país democrático como aquel en el cual las decisiones sí respetan, sí consideran y tienen fundamento en la opinión del pueblo (12\%). Asimismo, se "respeta al pueblo", "el pueblo es el gobernante", "se respetan los derechos", las leyes existen y se respetan, promueven los valores, la comunicación y la información del pueblo.

Tabla 14

¿Qué podemos hacer para que el país sea más democrático?

\begin{tabular}{lcc}
\hline \multicolumn{1}{c}{ Categoría } & Frecuencia & $\%$ \\
\hline Involucrar al pueblo en las decisiones & 29 & 18.2 \\
Ser más participativo y crítico & 16 & 10.0 \\
Cambiar aspectos políticos y personales & 14 & 8.8 \\
Hacer uso del derecho al voto & 12 & 7.5 \\
Respetarnos todos & 12 & 7.5 \\
Fomentar y practicar los valores & 7 & 4.4 \\
Eliminar la corrupción & 6 & 3.8 \\
Cambiar de gobernantes & 5 & 3.1 \\
Eliminar la discriminación & 5 & 3.1 \\
Solucionar los problemas del pueblo & 4 & 2.5 \\
No dejarse dominar & 4 & 2.5 \\
Luchar para ser escuchados & 4 & 2.5 \\
Manifestarse & 4 & 2.5 \\
Hacer conciencia & 4 & 2.5 \\
Fomentar la cultura de paz y democracia & 2 & 1.3 \\
Organizar las comunidades & 2 & 1.3 \\
Dar el ejemplo & 2 & 1.3 \\
Hacer valer los derechos & 2 & 1.3 \\
Mayor transparencia & 2 & 1.3 \\
Otros & 159 & 7.5 \\
No responde & & 7.0 \\
\hline Total & 2 & \\
\hline
\end{tabular}


doi: http://dx.doi.org/10.15359/ree.19-1.11

URL: http://www.una.ac.cr/educare

CORREO: educare@una.cr

Para construir un país más democrático, el estudiantado de la Universidad Nacional consultado sugiere, tal y como se presenta en la tabla 14 en orden de frecuencia, lo siguiente: involucrar al pueblo en las decisiones, ser más participativo y crítico, cambiar aspectos políticos y personales, hacer uso del derecho al voto, respetarnos todos, fomentar y practicar los valores, eliminar la corrupción, cambiar de gobernantes, eliminar la discriminación, solucionar los problemas del pueblo, no dejarse dominar, luchar para ser escuchados, manifestarse, hacer conciencia, fomentar la cultura de paz y democracia, organizar las comunidades, dar el ejemplo, hacer valer los derechos, mayor transparencia, entre otros con menor frecuencia.

Llama la atención la inconsistencia que existe entre los datos aportados por las personas consultadas y la información encontrada en la revisión bibliográfica, específicamente en cuanto a que en si bien es cierto la población en general, manifiesta que sí existe democracia, el uso que hacen de ella se limita exclusivamente a emitir el voto; pero no a una verdadera participación en la cotidianidad, en el centro educativo o en asuntos del país.

Tabla 15

¿Cuál es el principal problema que tenemos en Costa Rica?

\begin{tabular}{lcc}
\hline \multicolumn{1}{c}{ Categoría } & Frecuencia & $\%$ \\
\hline La corrupción/ No hay transparencia en las acciones & 34 & 19.6 \\
Gobernantes no toman en cuenta la opinión del pueblo & 19 & 11.0 \\
Problemas sociales: La inseguridad y delincuencia, Drogas/ Alcohol, Pobreza/ & 23 & 13.3 \\
Desempleo/ La violencia & & \\
Los gobernantes que tenemos & 9 & 5.2 \\
Nos quejamos pero no hacemos nada para cambiar & 9 & 5.2 \\
Manejo de influencias y abuso de poder & 7 & 4.0 \\
La educación & 7 & 4.0 \\
El conformismo del pueblo & 6 & 3.5 \\
La desigualdad & 6 & 3.5 \\
El gobierno satisface solo sus necesidades & 5 & 2.9 \\
No hay respeto & 4 & 2.3 \\
\hline
\end{tabular}

Continúa... 


\begin{tabular}{|c|c|c|}
\hline Categoría & Frecuencia & $\%$ \\
\hline Involucrar a otros países en las decisiones & 3 & 1.7 \\
\hline El sistema o estructura política & 3 & 1.7 \\
\hline No se satisfacen necesidades del pueblo & 3 & 1.7 \\
\hline La desconfianza & 3 & 1.7 \\
\hline No hay comunicación & 3 & 1.7 \\
\hline La doble moral & 3 & 1.7 \\
\hline El abstencionismo & 2 & 1.2 \\
\hline Otros & 9 & 5.3 \\
\hline No responde & 13 & 7.5 \\
\hline No sabe & 2 & 1.2 \\
\hline Total & 173 & 100.0 \\
\hline
\end{tabular}

En un sondeo realizado por el Instituto de Estudios Interdisciplinarios de la Niñez y la Adolescencia (2005), con niños y niñas escolares, previo a las elecciones en el año 2006, ellos y ellas priorizan los siguientes problemas: la drogadicción (195 respuestas), la pobreza (169 respuestas), robos y delincuencia (143), la contaminación (73), los presidentes (72), la migración (67), huecos en las carreteras (64), desempleo (23), abuso a niños y niñas (19), la economía (19), el TLC (15), la prostitución (9), vivienda (6), entre otros (21).

En esta misma línea de análisis, se deduce cierta coincidencia en las respuestas brindadas por el estudiantado de la Universidad Nacional colaborador en el sondeo que nos ocupa y contenidas en la tabla 15. Esto es, que existen algunas similitudes con los problemas que aún aquejan al país ocho años después, por ejemplo, la presencia de problemas sociales tales como la inseguridad, delincuencia, drogadicción, consumo de alcohol, pobreza, desempleo y violencia.

De la misma manera resaltan nuevas problemáticas como la corrupción en el manejo de influencias y abuso de poder, la falta de transparencia en las acciones, el tener gobernantes que no toman en cuenta la opinión del pueblo, gobernantes con acciones y decisiones que no son del agrado del pueblo y "no se satisfacen necesidades con igualdad" "solo por intereses personales". 
doi: http://dx.doi.org/10.15359/ree.19-1.11

URL: http://www.una.ac.cr/educare

CORREO: educare@una.cr

Posiblemente producto de lo antes mencionado, en la actualidad se visualiza un pueblo cada vez más conformista, que "se queja pero no hace nada para cambiar", que es desconfiado y que muestra cada vez más abstencionismo en el uso de su derecho a elegir, según lo comentan los participantes.

En relación con este tema, es interesante visualizar que las principales problemáticas que existen en Costa Rica, mencionadas tanto por las personas menores de edad, como por la población estudiantil universitaria, están consideradas en el Plan de Gobierno de la actual administración cuyo lema es el "trabajo, progreso y alegría" para lo cual divide las necesidades del país en tres pilares: primero, "Luchar contra la corrupción y fortalecer un Estado transparente y eficiente"..., segundo, "Impulsar el crecimiento económico del país y generar más y mejores empleos" y finalmente, "reducir la desigualdad y eliminar la pobreza extrema", vinculándolos a una serie de acciones concretas para "rescatar a Costa Rica" (Solís, 2014, párr. 1-3).

Como contraparte, cabe señalar, que los planes de gobierno de los candidatos contrincantes al Gobierno actual en el período en que se llevó a cabo la campaña electoral, también hacían un reconocimiento claro de las problemáticas del país antes señaladas.

El contenido de la tabla 15, pone en evidencia la claridad que tiene la población costarricense acerca de las situaciones que aquejan al país, así como de la necesidad de unificar esfuerzos en todas las esferas para combatir y luchar por un país mejor y equitativo para todos y todas las personas que habitamos en él.

Tabla 16

¿Cómo podemos solucionar el problema?

\begin{tabular}{lcc}
\hline \multicolumn{1}{c}{ Categoría } & Frecuencia & $\%$ \\
\hline Cambiando a los gobernantes & 8 & 14.0 \\
La educación & 6 & 10.5 \\
Cambio de mentalidad & 4 & 7.0 \\
Implementando leyes & 4 & 7.0 \\
Tomando decisiones & 3 & 5.3 \\
Unirnos/ Que el pueblo se involucre & 5 & 3.8 \\
Velar por la niñez & 2 & 3.5 \\
\hline
\end{tabular}

Continúa... 


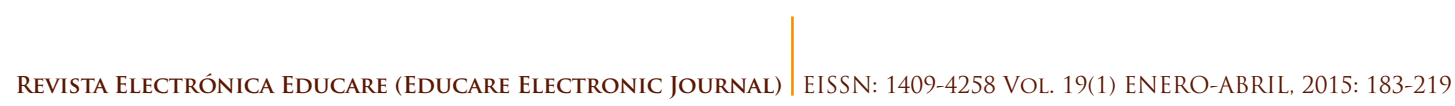

doi: http://dx.doi.org/10.15359/ree.19-1.11

URL: http://www.una.ac.cr/educare

CORREO: educare@una.cr

\begin{tabular}{lcc}
\hline \multicolumn{1}{c}{ Categoría } & Frecuencia & $\%$ \\
\hline Eliminar la corrupción & 2 & 3.5 \\
Inculcando valores/ Igualdad & 3 & 5.3 \\
Planes y programas efectivos & 2 & 3.5 \\
Castigar & 2 & 3.5 \\
Manifestándose /Que se escuche al pueblo & 2 & 3.6 \\
Nuevas estrategias & 1 & 1.8 \\
Incentivando al voto & 1 & 1.8 \\
Determinación de prioridades & 1 & 1.8 \\
Quitar el monopolio & 1 & 1.8 \\
Políticas neoliberales & 1 & 1.8 \\
Crear buenas bases & 1 & 1.8 \\
Brindar más información & 1 & 1.8 \\
Dejar de hacer las cosas incorrectas & 57 & 1.8 \\
Prevención & 1 & 8.8 \\
Otros & 1 & 1.8 \\
\hline Total & 1 & \\
\hline
\end{tabular}

Las respuestas que se brindan como propuesta para superar los problemas citados en la tabla 16, son diversas, nótese en la tabla 17 que algunas son alusivas a los gobiernos, desde cambiar personas y planes de gobierno, hasta crear más leyes que regulen las acciones; otras tienen que ver con la actitud y compromiso que debe asumir el pueblo con miras a lograr el cambio y, en menor porcentaje, van dirigidas al sector educación y a la formación en valores. 
REVISTA ELECTRÓNICA EdUCARE (EDUCARE ELECTRONIC JOURNAL) EISSN: 1409-4258 VOL. 19(1) ENERO-ABRIL, 2015: 183-219

doi: http://dx.doi.org/10.15359/ree.19-1.11

URL: http://www.una.ac.cr/educare

CORREO: educare@una.cr

Tabla 17

¿Qué recomendaciones le haría al futuro presidente de la República?

\begin{tabular}{lcc}
\hline \multicolumn{1}{c}{ Categoría } & Frecuencia & $\%$ \\
\hline $\begin{array}{l}\text { Que se escuche/ tome en cuenta al pueblo /Mejor comunicación/relación con el } \\
\text { pueblo /Trabajar en conjunto }\end{array}$ & 50 & 25.8 \\
Conocer/Atender las necesidades/ Buscar el bienestar/ Que trabajen para el pueblo & 38 & 19.6 \\
Que haya valores/ igualdad / compromiso & 17 & 8.8 \\
Que se invierta en educación/niñez /Invertir mejor los recursos & 13 & 6.7 \\
Que se elimine la corrupción/chorizo (corrupción) & 12 & 6.2 \\
Que cumplan lo que prometen & 11 & 5.6 \\
Mejorar/Cambiar & 7 & 3.6 \\
Que haya buenos gobernantes /Cambiar gobernantes & 6 & 3.1 \\
Problemas sociales: Eliminar delincuencia/violencia /Que se elimine la pobreza/ & 3 & 1.5 \\
Mayor seguridad & & \\
Que no se dejen llevar por los demás & 3 & 1.5 \\
Confiar en Dios & 2 & 1.0 \\
Mente abierta & 2 & 1.0 \\
Otros & 15 & 7.7 \\
No sabe & 1 & 0.5 \\
No responde & 13 & 6.7 \\
\hline Total & 193 & 100.0 \\
\hline
\end{tabular}

De la misma manera los niños y niñas en el sondeo realizado por el Instituto de Estudios Interdisciplinarios de la Niñez y la Adolescencia (2005), le recomendaron al futuro presidente en primer lugar que cumpla lo que promete (14.9\%), que luche contra la pobreza y ayude a los necesitados (10.4), "que no sea corrupto" (9.7\%), "que haga casas" (2.6\%), "que ponga mano dura" (7.2\%), "que sea buen presidente" (4.9\%), "que solucione los problemas" (3.9\%), "que ayude al país y cuide a Costa Rica" (3.3\%), "que piense" (2.0), "que arregle carreteras" (5.9\%), "que elimine la drogadicción y el alcoholismo" (4.3\%), "que atienda la contaminación" (3.6\%), "que tengamos más seguridad" (3.3\%), "que mejore la educación" (3.1\%), "menos migración" (2.9\%), "que haya más trabajo" (2.4\%), "que nos dé participación" (2.1\%), "que lo haga con ganas" (1.7\%), "que haga justicia y que sea justo" (1.8\%), "que ayude a los niños y adolescentes" (1.7\%), "que mejore la economía" (1.5\%), "que no haya violencia" (1.0\%), entre otros con menor porcentaje. 
Por su parte y tal como se observa en la tabla 17, la población de jóvenes que colaboró en el presente sondeo, coincide con algunas de las recomendaciones que los niños y niñas sostienen. Además, incorporan otros elementos: solicitan al futuro presidente "que escuche", que tome en cuenta, que tenga mejor comunicación, relación y que "trabajen en conjunto con el pueblo". En otra categoría se agrupan las respuestas que le sugieren al presidente que conozca y atienda las necesidades en pro del bienestar del país, que promueva la formación en valores, subrayando la igualdad y el compromiso, valores estrechamente relacionados con la eliminación de la corrupción y el cumplimiento de las promesas hechas en campaña.

De igual manera, hace referencia el $6.7 \%$ a la importancia de la inversión de recursos en educación, niñez y en actuar de la mejor manera a fin de que beneficie efectivamente a estas poblaciones. Proponen, también, que sea eliminada la delincuencia, la violencia, la pobreza y la inseguridad ciudadana, con lo cual se visualiza una clara conciencia de las problemáticas y necesidades del país.

\section{Conclusiones y recomendaciones}

Acerca del significado de la democracia para el estudiantado de las diversas carreras de grado de la Universidad Nacional de Costa Rica, se tiene que es el derecho del pueblo a elegir y tomar decisiones acerca de los temas de orden social, político, económico y cultural. Es la libertad de expresión, opinión y participación en los diferentes ámbitos que conforman la sociedad, basándose en la igualdad, la libertad, el respeto, el voto y la voz del pueblo. Ello es coincidente con la teoría revisada, la cual atribuye el poder de participación a la sociedad conformada por un grupo de iguales con los mismos derechos y deberes. Además, se visualiza a la ciudadanía con posibilidad de elegir a sus autoridades por medio del voto o sufragio, en el marco del respeto a sus derechos.

- La población participante visualiza un país democrático como aquel en el que existe libertad de expresión (voz), de escogencia de las autoridades gubernamentales (voto), las personas son escuchadas, respetadas y sus opiniones son tomadas en cuenta para decidir. Asimismo, se respetan los derechos, las leyes que existen y se promueven los valores, lo cual es reforzado teóricamente al concebirse un país democrático como aquel donde se ejerce la libertad, la igualdad y la participación, sin discriminar por razones de ninguna clase, con el objetivo de lograr un equilibrio en la distribución de poder.

- De igual manera, lo dicho por la comunidad estudiantil refuerza lo planteado a nivel teórico, en cuanto a que la democracia abarca los ámbitos político, económico, social y cultural y busca permanentemente la realización de metas individuales y grupales de las personas, familias y sociedad sin distingo ni discriminación o exclusión de ningún tipo. 
doi: http://dx.doi.org/10.15359/ree.19-1.11

URL: http://www.una.ac.cr/educare

CORREO: educare@una.cr

Según la teoría, la toma de decisiones es un proceso que implica la recopilación de datos para clarificar los conflictos y las posibles alternativas de solución que conllevan a actuar. Parece obvio que a partir de las respuestas obtenidas, los conflictos están presentes en todos los ámbitos de la vida, esto es, la familia, la comunidad, el centro educativo y la sociedad en general.

- Existe coincidencia entre las respuestas obtenidas y la teoría, acerca de que en una familia democrática las decisiones deben ser tomadas con la opinión de todos y todas sus miembros, respetando lo que la mayoría considere oportuno, lo que evidencia la importancia de la libertad de expresión y el respeto, así como los valores de la justicia, la igualdad, la comunicación y la participación. No obstante, los datos parecen sugerir que algunos hijos e hijas no participan de las decisiones que se toman ya que son las figuras parentales quienes deciden en cuáles les concierne o no participar.

El modelo de familia democrática es, según la teoría, el más adecuado y sano para la convivencia; sin embargo, es considerado el más difícil de implementar, pues es un desafío en cuanto al establecimiento de límites y normas, toma de decisiones conjuntas y el manejo de la autoridad ejercida con respeto, libertad y amor. Es importante señalar que una mayoría de la población participante resalta la trascendencia de que el grado de involucramiento que tengan sea coherente con la capacidad, madurez y edad de los hijos e hijas, de conformidad, con la autonomía progresiva expresada en el nuevo paradigma de derechos de las personas menores edad.

- La teoría sugiere que el estilo de familia democrática es el que debe existir en los hogares para que así prevalezca la democracia en la sociedad, especialmente si se caracteriza por la comunicación constante, la comprensión, el respeto, la equidad, la libertad, el afecto, la participación, la igualdad y la colaboración de todas las personas que la conforman, es decir, una familia basada en los valores que fortalecen la resolución asertiva de conflictos y, por consiguiente, la convivencia armoniosa y pacífica.

- Conceptualmente, se plantea que en el salón de clase las decisiones se toman en grupo, ya que se convive grupalmente y que deben estar basadas en reglamentos, en las acciones de cada persona a lo interno de la clase, incluido el personal docente y en la definición de conflictos y posibles soluciones y consecuencias que se deriven de estas, a fin de garantiza el respeto, el orden, participación, la libertad y la igualdad entre otros.

- Es importante resaltar que, de las opiniones recopiladas, se rescatan tres niveles de participación en la toma de decisiones: En primer lugar, las de naturaleza académica, cuya responsabilidad la delegan en el profesorado y que tienen que ver con la organización de la clase, el diseño de contenidos, las estrategias, la metodología, el aprendizaje, la evaluación y la mediación, así como los límites, reglas y valores presentes en la dinámica 
de aula. En segundo lugar, las que involucran a los actores educativos dentro del aula, y que promueven un buen ambiente, la resolución de problemas y el bienestar de todos y todas. Finalmente, están las que se atribuyen como responsabilidad propia, tales como, las que "les involucra", las "relacionadas con los cursos", "los programas de los cursos", lo relacionado con "el estudio" y en la "evaluación". Es importante resaltar la urgente necesidad manifestada por la población estudiantil, para que se le reconozca el derecho a tomar decisiones; no obstante, es preocupante que las respuestas que brindan acerca de las decisiones que les corresponden evidencian ambigüedad, poca claridad acerca del significado y del rol que les compete, lo cual las hace poco viables y difíciles de cumplir, y limitantes de las posibilidades reales de participación.

- En relación con lo anterior, llama la atención que según la teoría consultada, en la actualidad, el papel que se le asigna a la población docente varió sustancialmente, por cuanto se espera que facilite y apoye la labor y el liderazgo de sus estudiantes, de tal manera que haya igualdad. Así se facilita el aprendizaje y desarrollo integral de las habilidades personales. Esto lleva a suponer que el personal docente es el llamado a concienciar a sus educandos acerca de la gama de posibilidades que tienen para decidir, creando con ello una cultura democrática en el aula que trascienda todos los ámbitos en los que ellos y ellas se desenvuelvan.

- Las personas consultadas son del criterio de que para construir un país más democrático, se requiere involucrar al pueblo en las decisiones, ser más participativo y crítico, hacer uso del derecho al voto, respetar, fomentar y practicar valores, eliminar la corrupción, solucionar los problemas del pueblo, fomentar la cultura de paz y democracia, organizar las comunidades y hacer valer los derechos, entre otros.

Al respecto, tanto la teoría como los resultados obtenidos, señalan que un país democrático se caracteriza por los siguientes aspectos: tener elecciones libres y justas, el sufragio es universal, los ciudadanos pueden postularse candidatos a la presidencia, se debe contar con la información necesaria.

Respecto a los principales problemas que afectan a Costa Rica, según el grupo participante, son: en primera instancia, la inseguridad, la delincuencia, la drogadicción, el consumo de alcohol, la pobreza, el desempleo y la violencia. Aunado a estos se mencionan la corrupción, el manejo de influencias, el abuso de poder y la falta de transparencia.

Cabe pensar que existe una sensación generalizada de disconformidad con la manera en que las administraciones han gobernado el país en los últimos años, lo cual es reforzado a nivel teórico, ya que evidencia que en el transcurso del tiempo, las personas han experimentado cada vez mayor frustración ante el sistema democrático que impera, debido al ineficiente trabajo de los partidos políticos de turno. Esto es coincidente con 
doi: http://dx.doi.org/10.15359/ree.19-1.11

URL: http://www.una.ac.cr/educare

CORREO: educare@una.cr

los datos del sondeo, que dan cuenta de que el pueblo es cada vez más conformista, "se queja pero no hace nada para cambiar", es desconfiado y se muestra cada vez más renuente a ejercer el derecho que tiene a emitir su voto.

- Cabe pensar que para fortalecer una democracia sostenible y la motivación de la ciudadanía a participar activamente en los procesos democráticos, se requiere que el país resuelva sus problemas procurando niveles óptimos de desarrollo humano e incentivando la confianza, la esperanza, el liderazgo, las metas claras y el espíritu cívico, el acceso a la información, el seguimiento a las acciones gubernamentales y el cumplimiento eficaz, efectiva y transparente de la gestión.

- Lo anterior guarda relación con las recomendaciones que brindan los estudiantes y las estudiantes al futuro presidente, orientadas a que escuche, que tenga mejor comunicación y que trabajen en conjunto con el pueblo para satisfacer las necesidades y demandas en pro del bienestar general de la población.

\section{Recomendaciones}

- Con base en la definición planteada de democracia como el gobierno del pueblo, se considera de fundamental importancia el que las personas participen activamente en la toma de decisiones, en la resolución de conflictos, en la búsqueda de su bienestar, en la consolidación de una sociedad más justa y solidaria, en la reducción de las brechas existentes y en la identificación y aprovechamiento de las oportunidades que se les presentan para ejercer sus derechos que trascienden la emisión del voto.

- Los ambientes democráticos que faciliten la participación, el respeto, la expresión, la tolerancia, la disciplina, el respeto por las normas, el reconocimiento de los grupos de estudiantes como personas capaces de aportar a la construcción del bien común se deben promover a lo interno de las aulas.

- Será posible hablar de una sociedad democrática, cuando en las familias exista una comunicación asertiva, basada en la comprensión, el respeto, la equidad, la libertad, el afecto, la participación, la igualdad y la colaboración, todo lo cual propicia una convivencia armoniosa y pacífica.

- La formación y el fortalecimiento de los valores cívicos y democráticos que conlleven a la existencia de una verdadera participación ciudadana debe iniciarse desde la primera infancia en los centros educativos e irse reforzando en los niveles superiores, lo cual es coherente con lo estipulado en los fines de la Ley Fundamental de Educación (1957). 
- De igual manera le compete, a las instituciones de educación superior, fortalecer en sus estudiantes la transparencia en sus acciones, el acceso a la información, la participación en procesos y entidades federativas, sociales y comunales, el derecho a elegir y expresarse libremente, es decir, una participación cívica y civilizada en el marco de la legalidad; así como, la vigilancia del gobierno como parte de la sociedad, la participación activa en la construcción de la agenda nacional y en el diseño, implementación y evaluación de las políticas públicas vigentes.

- $\quad$ Quienes gobiernan tienen el deber de promover y defender la democracia para que sea una realidad, por lo que deben jugar un papel determinante en la búsqueda de soluciones, alternativas y propuestas tendientes a disminuir la brecha social existente en el país.

- Las personas que estén en el ejercicio del poder deben velar porque su propuesta de gobierno sea ejecutada satisfactoriamente, evaluando la viabilidad de las acciones y la idoneidad de las personas responsables de llevarlas a cabo lo cual hace pensar que conlleve al convencimiento, credibilidad y motivación de la ciudadanía ante los presentes y futuros procesos democráticos.

- A fin de fortalecer el sistema democrático costarricense, es imperativo que el pueblo retome el espíritu cívico, de tal manera que todos y todas hagan uso del deber y derecho a participar colectiva e individualmente en la elección de las autoridades gubernamentales y en todas aquellas acciones que buscan el desarrollo económico, social y político del país.

\section{Referencias}

Álvarez, Ó. (2010). Valores, humanismo y democracia. San José, Costa Rica: Lara Segura y Asociados.

Arias, O. (2010). La democracia se construye en las aulas. Recuperado de http://laoveja100. wordpress.com/2011/06/09/la-democracia-se-construye-en-las-aulas/

Asamblea Legislativa de la República de Costa Rica. (1957). Ley Fundamental de Educación. N ${ }^{\circ}$ 2160. Recuperado de http://www.oei.es/quipu/costarica/Ley 2160.pdf

Cepeda. S. (2011-2012). Las universidades como promotoras de la transparencia y participación ciudadana y su impacto en la transformación del ámbito social y público en México. Revista Bien Común, 204-205(18). 47-55. Recuperado de http://www.fundacionpreciado. org.mx/biencomun/bc204-205/S Cepeda.pdf

Código de la Niñez y Adolescencia. Ley 7739. (6 de febrero de 1998). La Gaceta N²6. Recuperado de http://www.tse.go.cr/pdf/normativa/codigodelaninez.pdf 
REVISTA EleCtrónica EdUCARE (EDUCARE EleCtronic JOURNAL) EISSN: 1409-4258 VOL. 19(1) ENERO-ABRIL, 2015: 183-219

doi: http://dx.doi.org/10.15359/ree.19-1.11

URL: http://www.una.ac.cr/educare

CORREO: educare@una.cr

Diego, A. (2010). Historia de la democracia en Costa Rica. BuenasTareas.com. Recuperado de http://www.buenastareas.com/ensayos/Democracia-Costa-Rica/928315.html

Fondo Internacional de Emergenia de la Naciones Unidas para la Infancia (UNICEF). (2005). Convención sobre de los derechos el niño (6a ed.). Madrid: Autor. Recuperado de http:// www.unicef.es/sites/www.unicef.es/files/CDN 06.pdf

Furlong, W. L. (2008). Evolución de la democracia costarricense: Partidos políticos y campañas electorales (1982-2006). San José, Costa Rica: EUCR.

García, M. (s. f.). Familia, escuela y democracia: Los pilares de la participación infantil. Recuperado de http://www.iin.oea.org/IIN/cad/Participacion/pdf/Documento1.pdf

Instituto de Estudios Interdisciplinarios de la Niñez y la Adolescencia (INEINA). (2005). Aplicación de los derechos de los niños, niñas y adolescentes. Foro construyendo democracia en las familias, los centros educativos y las comunidades. Universidad Nacional de Costa Rica. Documento inédito.

Luengo, F. y Moyá, J. (2008). Escuela, familia, comunidad: Claves para la acción. Madrid: Wolters Kluwer.

Malave, C. (21 de mayo de 2012). Toma de decisiones. [Mensaje en un blog]. Recuperado de http://faseupel2012.blogspot.com/2012/05/rol-del-docente-como-evaluador.html

Morales, F. (2008). Costa Rica: Democratizando la democracia. San José, Costa Rica: EUNED.

Muñoz, N. (28 de octubre, 2013). El país con menor participación ciudadana de América Latina. BBC Mundo. Recuperado de http://www.bbc.co.uk/mundo/noticias/2013/10/131025 america latina costa rica politica.shtml

Obregón, E. (2009). Gobernar para el pueblo: Meditaciones sobre democracia, libertad, valores y derechos. San José, Costa Rica: EUNED.

Pellegrini, M. V. (2009). Contactos entre la autonomía progresiva y la capacidad para contratar de personas menores de edad. Revista Derecho de Familia. Revista Interdisciplinaria de Doctrina y Jurisprudencia, 42, 85-97. Recuperado de http://www.dupratpellegrini.com. ar/publicaciones/MVP-Contactos-entre-la-autonomia-progresiva-y-la-capacidad-paracontratar-de-personas-menores-de-edad-RDF-2009.pdf

Prieto, M. (2003). Educación para la democracia en las escuelas: Un desafío pendiente. Revista Iberoamericana de Educación. Recuperado de http://www.rieoei.org/ deloslectores/497Prieto.pdf 
Ramírez, A. (2011). El interés superior de la persona menor de edad en los convenios internacionales de restitución de personas menores de edad: Convenio sobre aspectos civiles de la sustracción internacional de menores y convención interamericana sobre restitución internacional de menores. Revista de Familia Poder Judicial de Costa Rica. Derecho de familia, 165-180. Recuperado de http://sitios.poder-judicial.go.cr/ escuelajudicial/Descargas/Revista de Familia.pdf

Ramírez, M. A. (2005). Padres y desarrollo de los hijos: Prácticas de crianza. Estudios pedagógicos, 31(2), 167-177. Recuperado de http://www.scielo.cl/scielo.php?script=sci arttext\&pid=S0718-07052005000200011\&lng=es\&nrm=iso\&tlng=es

Rodríguez, A. (29 de agosto de 2011). La familia democrática: Ideal [Mensaje en un blog]. Recuperado de http://habitatadolescente.blogspot.com/2011/08/la-familia-democraticaideal.html

Rodríguez, O. M. (2009). Educación para los derechos humanos, para la democracia y para la paz (2a ed.). San José, Costa Rica: Coordinación Educativa y Cultural Centroamericana, CECC/ SICA. Recuperado de http://www.ncarballo.info/volumen19.pdf

Solís, L. G. (2014). Plan rescate. Trabajo, progreso y alegría. Recuperado de http://www. archivoelectoral.org/documentos/plan-de-trabajo-progreso-y-alegria/849

Villegas, E. (1996). Educación de valores éticos y democráticos en las escuelas: La situación actual en Latinoamérica. Pensamiento Educativo, 18(1), 263-286. Recuperado de https://docs. google.com/viewer?url=http://pensamientoeducativo.uc.cl/files/journals/2/articles/59/ public/59-149-1-PB.pdf\&chrome=true

\section{Cómo citar este artículo en APA:}

Morales-Ramírez, M. E., Castro-Pérez, M. y Bolaños-Mora, M. (enero-abril, 2015). Perspectiva del estudiantado universitario de las diversas carreras de la Universidad Nacional acerca de la democracia en la familia, el centro educativo y el país. Revista Electrónica Educare, 19(1), 183-219. doi: http://dx.doi.org/10.15359/ree.19-1.11

Nota: Para citar este artículo en otros sistemas puede consultar el hipervínculo "Como citar el artículo" en la barra derecha de nuestro sitio web:

http://www.revistas.una.ac.cr/index.php/EDUCARE/index 